The International Journal of Engineering and Science (IJES)

|| Volume || 6 || Issue || 5 || Pages || PP 16-23 || 2017 ||

ISSN (e): $2319-1813$ ISSN (p): $2319-1805$

THE IJES

\title{
Markov Models in Homeopathic Treatment on Pet Animals
}

\author{
S. Vijaya Bhaskara Raju ${ }^{1}$, P. Shiva Prasad ${ }^{2}$, C. Jayalakshmi ${ }^{1}$ \\ ${ }^{I}$ Department of Statistics, Osmania University, $H y d$. \\ ${ }^{2}$ Homeopathy Practitioner, Hyderabad.
}

\begin{abstract}
Early Homeopaths treated both humans and animals. So when we considered data on Pet dogs Physical problems and treatment given through homeopathy medicine and analyzed the data using Markov Models. The objective of this research work is to establish through statistical analysis how effectively homeopathy medicine is useful in treating different physical ailments of pet dogs in the present contemporary situation. Our analysis established more than $90 \%$ effectiveness of the medicine in solving the above mentioned problems.
\end{abstract}

\section{INTRODUCTION}

Early Homeopaths treated both humans and animal patients. Numerous reports of treatment of Dogs, Cats, Birds and Cattle have been presented in the works of homeopathy pioneers.

In Europe Continent in different countries homeopathy is being practiced and research articles are also published. But to the extent of our research, in India we could not find any such research articles published. Hence this work is taken up on the recorded data provided by P. Shiva Prasad, a young enterprising Homeopathy doctor, on treatment of pet dogs.

\section{STATISTICAL ASPECT}

Fix and Neymann (1951) applied Markov Model to study recovery, relapse and death possibilities of Cancer patients. As the present data satisfies Markov Property and is also time homogeneous, we adopted a "time homogeneous Markov Chain" to analyze present data. Data is collected on 747 pet dogs treatment. The observed physical problems in these pet dogs are categorized as follows for the purpose of analysis. They are

1. Respiratory Problems

2. Orthopedic Problems

3. Skin and Skin related Problems

4. Digestive Problems

5. Central Nervous system Problems and Ear and Eye related Problems.

For each of these categories, we applied Markov model and assessed effectiveness of homeopathy medicine in terms of probabilities.

\section{MARKOV MODEL}

In this analysis we identified 5 states in the state space $S$ and are as described below.

State 0 - Being Under treatment initially/at recurrence

State 1 - Being Under observation

State 2 - Cured to the extent curable/ possible to cure

State $3-100 \%$ recovery

State 4 - Death of the dog.

State ' 2 ' is defined keeping in view the possibility of a particular disease or complaint cannot be cured beyond certain level due the factors like age of the dog, response of the nervous system of the dog, gender, breed etc. It may be noted that when a transition occurs between the states, during the treatment, only the following types of transitions are possible. (0-1), (0-2), (0-3), (0-4), (1-0), (1-2). Let

$\mathrm{P}_{01}$ - Transition probability for $0-1$

$\mathrm{P}_{02}$ - Transition probability for $0-2$

$\mathrm{P}_{03}$ - Transition probability for $0-3$

$\mathrm{P}_{04}$ - Transition probability for $0-4$

$\mathrm{P}_{10}$ - Transition probability for 1-0

$\mathrm{P}_{12}$ - Transition probability for $1-2$ 
Let the subject be initially in the state ' 0 '. Define

\section{KOLMOGOROV EQUATIONS:-}

$\mathrm{P}_{\mathrm{n}}(\mathrm{t})=\mathrm{P}[$ Subject found in state $\mathrm{n}$ at time ' $\mathrm{t}$ ']

Forward Kolmogorov Equations for this process can be written for the five different states in the state space $\mathrm{S}=$ $\{0,1,2,3,4\}$ as given below.

$$
\begin{aligned}
& \mathrm{P}^{\prime}(\mathrm{t})=-\left(\mathrm{P}_{01}+\mathrm{P}_{02}+\mathrm{P}_{03}+\mathrm{P}_{04}\right) \mathrm{P}_{0}(\mathrm{t})+\mathrm{P}_{10} \mathrm{P}_{1}(\mathrm{t}) \\
& \mathrm{P}_{1}^{\prime}(\mathrm{t})=-\left(\mathrm{P}_{10}+\mathrm{P}_{12}\right) \mathrm{P}_{1}(\mathrm{t})+\mathrm{P}_{01} \mathrm{P}_{0}(\mathrm{t}) \\
& \mathrm{P}^{\prime}{ }_{2}(\mathrm{t})=\mathrm{P}_{02} \mathrm{P}_{0}(\mathrm{t})+\mathrm{P}_{12} \mathrm{P}_{1}(\mathrm{t}) \\
& \mathrm{P}^{\prime}{ }^{\prime}(\mathrm{t})=\mathrm{P}_{03} \mathrm{P}_{0}(\mathrm{t}) \\
& \mathrm{P}^{\prime}{ }_{4}(\mathrm{t})=\mathrm{P}_{04} \mathrm{P}_{0}(\mathrm{t})
\end{aligned}
$$

To solve these equations for finite time, we use the Laplace transform. Let

$$
\phi_{n}(t)=\int_{0}^{\infty} e^{-\theta t} P_{n}(t) d t \quad \operatorname{Re}(\theta)>0
$$

Such that under the assumption $\mathrm{P}_{0}(0)=1$ and $\mathrm{P}_{\mathrm{n}}(0)=0 \forall \mathrm{n}=1,2,3$ and 4 . We have

$$
\begin{aligned}
\int_{0}^{\infty} e^{-\theta t} P_{\mathrm{o}}(t) d t & =\theta \phi_{\mathrm{o}}(\theta)-1 \\
\text { and } \int_{0}^{\infty} e^{-\theta t} P_{n}(t) d t & =\theta \phi_{n}(\theta) \quad \mathrm{n}=1,2,3 \text { and } 4
\end{aligned}
$$

Now by using forward Kolmogorov equations we get

$\theta \phi_{0}(\theta)-1=-\left(\mathrm{P}_{01}+\mathrm{P}_{02}+\mathrm{P}_{03}+\mathrm{P}_{04}\right) \phi_{0}(\theta)+\mathrm{P}_{10} \phi_{1}(\theta)$

$\theta \phi_{1}(\theta)=-\left(\mathrm{P}_{10}+\mathrm{P}_{12}\right) \phi_{1}(\theta)+\mathrm{P}_{01} \phi_{0}(\theta)$

$\theta \phi_{2}(\theta)=\mathrm{P}_{02} \phi_{0}(\theta)+\mathrm{P}_{12} \phi_{1}(\theta)$

$\theta \phi_{3}(\theta)=\mathrm{P}_{03} \phi_{0}(\theta)$

$\theta \phi_{4}(\theta)=\mathrm{P}_{04} \phi_{0}(\theta)$

From (4.7) we have

$$
\Rightarrow \phi_{1}(\theta)=\frac{P_{01} \phi_{0}(\theta)}{\left[\theta+P_{10}+P_{12}\right]}
$$

By substituting $\phi_{1}(\theta)$ in (4.6) we get

$$
\therefore \quad \phi_{0}(\theta)=\frac{\theta+P_{10}+P_{12}}{\left[\theta^{2}+B \theta+C\right]}
$$

where $\mathrm{B}=\mathrm{P}_{01}+\mathrm{P}_{02}+\mathrm{P}_{03}+\mathrm{P}_{04}+\mathrm{P}_{10}+\mathrm{P}_{12}$

$$
\text { and } \mathrm{C}=\mathrm{P}_{10} \mathrm{P}_{02}+\mathrm{P}_{10} \mathrm{P}_{03}+\mathrm{P}_{10} \mathrm{P}_{04}+\mathrm{P}_{12} \mathrm{P}_{01}+\mathrm{P}_{12} \mathrm{P}_{02}+\mathrm{P}_{12} \mathrm{P}_{03}+\mathrm{P}_{12} \mathrm{P}_{04}
$$

The denominator of (4.12) is a quadratic in $\theta$. Hence we can write

$$
\phi_{0}(\theta)=\frac{\theta+P_{10}+P_{12}}{\left(\theta-\xi_{1}\right)\left(\theta-\xi_{2}\right)}
$$

where $\xi_{1}=\frac{-B-\sqrt{B^{2}-4 A C}}{2 A}$ and $\xi_{2}=\frac{-B+\sqrt{B^{2}-4 A C}}{2 A}$

with $\quad \mathrm{A}=1$

$$
\begin{aligned}
& \mathrm{B}=\mathrm{P}_{01}+\mathrm{P}_{02}+\mathrm{P}_{03}+\mathrm{P}_{04}+\mathrm{P}_{10}+\mathrm{P}_{12} \\
& \mathrm{C}=\mathrm{P}_{10} \mathrm{P}_{02}+\mathrm{P}_{10} \mathrm{P}_{03}+\mathrm{P}_{10} \mathrm{P}_{04}+\mathrm{P}_{12} \mathrm{P}_{01}+\mathrm{P}_{12} \mathrm{P}_{02}+\mathrm{P}_{12} \mathrm{P}_{03}+\mathrm{P}_{12} \mathrm{P}_{04}
\end{aligned}
$$

Expressing the right hand side of (4.13) in partial fractions we can write

$$
\phi_{0}(\theta)=\frac{\xi_{1}+P_{10}+P_{12}}{\xi_{1}-\xi_{2}} \cdot \frac{1}{\theta-\xi_{1}}-\frac{\xi_{2}+P_{10}+P_{12}}{\xi_{1}-\xi_{2}} \cdot \frac{1}{\theta-\xi_{2}}
$$

This when inverted gives

$$
P_{0}(t)=\frac{1}{\xi_{1}-\xi_{2}}\left[\left(\xi_{1}+P_{10}+P_{12}\right) e^{\xi_{1} t}-\left(\xi_{2}+P_{10}+P_{12}\right) e^{\xi_{2} t}\right]
$$


Similarly from (4.11) and (4.13), by substituting the value of $\phi_{0}(\theta)$ in $\phi_{1}(\theta)$ we get

$$
P_{1}(t)=\frac{P_{01}}{\left(\xi_{1}-\xi_{2}\right)}\left[e^{\xi_{1} t}-e^{\xi_{2} t}\right]
$$

From (4.4) we know that

$\mathrm{P}_{3}^{\prime}(\mathrm{t})=\mathrm{P}_{03} \mathrm{P}_{0}(\mathrm{t})$

By integrating both sides we get

$$
P_{3}(t)=P_{03} \int P_{0}(t) d t
$$

From (4.15) and (4.17) we have

$$
\begin{aligned}
P_{3}(t) & =\frac{p_{03}}{\xi_{1}-\xi_{2}}\left\{\int\left[\left(\xi_{1}+P_{10}+P_{12}\right) e^{\xi_{1} t}-\left(\xi_{2}+P_{10}+P_{12}\right) e^{\xi_{1} t}\right] d t\right\} \\
& =\frac{P_{03}}{\xi_{1}-\xi_{2}}\left[\frac{\left(\xi_{1}+P_{10}+P_{12}\right) e^{\xi_{1} t}}{\xi_{1}}-\frac{\left(\xi_{2}+P_{10}+P_{12}\right) e^{\xi_{2} t}}{\xi_{2}}\right]+C
\end{aligned}
$$

where $\mathrm{C}$ is a constant of integration. By substituting $\mathrm{t}=0$, we get the value of $\mathrm{C}$ as

$$
\Rightarrow C=\frac{P_{03}\left[P_{10}+P_{12}\right]}{\xi_{1} \xi_{2}}
$$

From (4.18) and (4.19) we have

$$
\Rightarrow P_{3}(t)=P_{03}\left[\frac{P_{10}+P_{12}}{\xi_{1} \xi_{2}}+\frac{\left(\xi_{1}+P_{10}+P_{12}\right) e^{\xi_{1} t}}{\xi_{1}\left(\xi_{1}-\xi_{2}\right)}-\frac{\left(\xi_{2}+P_{10}+P_{12}\right) e^{\xi_{2} t}}{\xi_{2}\left(\xi_{1}-\xi_{2}\right)}\right]
$$

Similarly we get the value of $\mathrm{P}_{4}(\mathrm{t})$

$$
P_{4}(t)=P_{04}\left[\frac{P_{10}+P_{12}}{\xi_{1} \xi_{2}}+\frac{\left(\xi_{1}+P_{10}+P_{12}\right) e^{\xi_{1} t}}{\xi_{1}\left(\xi_{1}-\xi_{2}\right)}-\frac{\left(\xi_{2}+P_{10}+P_{12}\right) e^{\xi_{2} t}}{\xi_{2}\left(\xi_{1}-\xi_{2}\right)}\right]
$$

From (4.3) we know the value of $\mathrm{P}_{2}(\mathrm{t})$

$$
\mathrm{P}_{2}^{\prime}(\mathrm{t})=\mathrm{P}_{02} \mathrm{P}_{0}(\mathrm{t})+\mathrm{P}_{12} \mathrm{P}_{1}(\mathrm{t})
$$

By integrating both sides we get

$$
\begin{aligned}
P_{2}(t) & =P_{02} \int P_{0}(t) d t+P_{12} \int P_{1}(t) d t \\
= & \mathrm{T}_{1}+\mathrm{T}_{2} \text { (say) }
\end{aligned}
$$

$\mathrm{T}_{1}$ is similar to $\mathrm{P}_{3}(\mathrm{t})$, so

$$
T_{1}=P_{02} \int P_{0}(t) d t=P_{02}\left[\frac{P_{10}+P_{12}}{\xi_{1} \xi_{2}}+\frac{\left(\xi_{1}+P_{10}+P_{12}\right) e^{\xi_{1} t}}{\xi_{1}\left(\xi_{1}-\xi_{2}\right)}-\frac{\left(\xi_{2}+P_{10}+P_{12}\right) e^{\xi_{2} t}}{\xi_{2}\left(\xi_{1}-\xi_{2}\right)}\right]
$$

Now by substituting the value of $\mathrm{P}_{1}(\mathrm{t})$ from (4.16) in $\mathrm{T}_{2}$ we get

$$
\begin{aligned}
T_{2} & =P_{12} \int P_{1}(t) d t=P_{12} \int\left[\frac{P_{01}}{\xi_{1}-\xi_{2}}\left[e^{\xi_{1} t}-e^{\xi_{2} t}\right]\right] d t \\
& =\frac{P_{01} P_{12}}{\xi_{1}-\xi_{2}}\left[\frac{e^{\xi_{1} t}}{\xi_{1}}-\frac{e^{\xi_{2} t}}{\xi_{2}}\right]+C \text {, a constant of integration }
\end{aligned}
$$

In order to obtain the value of $\mathrm{C}$, we put the initial condition $\mathrm{t}=0$ in the above equation. So we get

$$
C=\frac{P_{01} P_{12}}{\xi_{1} \xi_{2}}
$$

From (4.24) and (4.25) we have

$$
T_{2}=P_{12} \int P_{1}(t) d t=P_{01} P_{12}\left[\frac{e^{\xi_{1} t}}{\xi_{1}\left(\xi_{1}-\xi_{2}\right)}-\frac{e^{\xi_{2} t}}{\xi_{2}\left(\xi_{1}-\xi_{2}\right)}+\frac{1}{\xi_{1} \xi_{2}}\right]
$$

From (4.22),(4.23) and (4.26) we have 


$$
\begin{aligned}
& P_{2}(t)=P_{02}\left[\frac{P_{10}+P_{12}}{\xi_{1} \xi_{2}}+\frac{\left(\xi_{1}+P_{10}+P_{12}\right) e^{\xi_{1} t}}{\xi_{1}\left(\xi_{1}-\xi_{2}\right)}-\frac{\left(\xi_{2}+P_{10}+P_{12}\right) e^{\xi_{2} t}}{\xi_{2}\left(\xi_{1}-\xi_{2}\right)}\right]+ \\
& P_{01} P_{12}\left[\frac{e^{\xi_{1} t}}{\xi_{1}\left(\xi_{1}-\xi_{2}\right)}-\frac{e^{\xi_{2} t}}{\xi_{2}\left(\xi_{1}-\xi_{2}\right)}+\frac{1}{\xi_{1} \xi_{2}}\right]
\end{aligned}
$$

(4.15),(4.16),(4.27),(4.20) and (4.22) are the derived Kolmogorov equations. Using them one can compute $P_{n}(t)$ for $\mathrm{n}=0,1,2,3,4$ for a specified ' $\mathrm{t}$ '.

\section{STATISTICAL ANALYSIS:-}

Let $\mathrm{P}_{\mathrm{jk}}$ be the one-step transition probability from state ' $\mathrm{k}$ ' to state ' $\mathrm{j}$ '. The transition probabilities are such that $\mathrm{P}_{\mathrm{jk}} \geq 0$ and $\sum_{k} P_{j k}=1 \quad \forall \mathrm{j}$ and are written in the matrix form as shown below.

$$
\mathbf{P}=\left(\begin{array}{cccccc}
p_{11} & p_{12} & \cdots & p_{1 k} & \cdots & \bar{p}_{1 m} \\
p_{21} & p_{22} & \cdots & p_{2 k} & \cdots & p_{2 m} \\
\cdots & \cdots & \cdots & \cdots & \cdots & \cdots \\
p_{j 1} & p_{j 2} & \cdots & p_{j k} & \cdots & p_{j m} \\
\cdots & \cdots & \cdots & \cdots & \cdots & \cdots \\
p_{m 1} & p_{m 2} & \cdots & p_{m k} & \cdots & p_{m m}
\end{array}\right)
$$

\subsection{Respiratory Problems}

Out of the total number of cases in 88 cases the subjects are suffering from different "Respiratory Problems" are arranged in the form of matrix as shown below depending on the nature of response observed in the subjects against the given treatment.

$$
\text { Matrix = } \begin{gathered}
0 \\
1 \\
2 \\
3 \\
4
\end{gathered}\left(\begin{array}{ccccc}
0 & 1 & 2 & 3 & 4 \\
0 & 2 & 31 & 52 & 3 \\
2 & 0 & 2 & 0 & 0 \\
0 & 0 & 33 & 0 & 0 \\
0 & 0 & 0 & 52 & 0 \\
0 & 0 & 0 & 0 & 0
\end{array}\right)
$$

The obtained one-step t.p.m is as given below

$$
\mathrm{P}_{1}=\quad \begin{aligned}
& 0 \\
& 1 \\
& 2 \\
& 3 \\
& 4
\end{aligned}\left(\begin{array}{ccccc}
0 & 1 & 2 & 3 & 4 \\
0.5 & 0 & 0.5 & 0 & 0 \\
0 & 0 & 1 & 0 & 0 \\
0 & 0 & 0 & 1 & 0 \\
0 & 0 & 0 & 0 & 1
\end{array}\right)
$$

The so obtained $\mathrm{P}_{\mathrm{jk}}$ 's are nothing but the Maximum Likelihood estimates of one-step transition probabilities.

\subsection{Orthopedic Problems:-}

Out of the total number of cases in 176 cases the subjects are suffering from different "Orthopedic Problems" are arranged in the form of matrix as shown below depending on the nature of response observed in the subjects against the given treatment. 


$$
\text { Matrix } \left.=3 \begin{array}{ccccc}
0 & 1 & 2 & 3 & 4 \\
0 & 8 & 86 & 81 & 1 \\
& 3 \\
3 & 0 & 5 & 0 & 0 \\
0 & 0 & 91 & 0 & 0 \\
0 & 0 & 0 & 81 & 0 \\
0 & 0 & 0 & 0 & 1
\end{array}\right)
$$

The obtained one-step t.p.m is as given below

$$
\mathrm{P}_{2}=\begin{gathered}
0 \\
0 \\
1 \\
2 \\
3 \\
4 \\
0
\end{gathered}\left(\begin{array}{ccccc}
0 & 0.04 & 0.48 & 0.47 & 0.01 \\
0.61 & 0 & 0.39 & 0 & 0 \\
0 & 0 & 1 & 0 & 0 \\
0 & 0 & 1 & 0 \\
0 & 0 & 0 & 1
\end{array}\right)
$$

\subsection{Skin related Problems:-}

Out of the total number of cases in 118 cases the subjects are suffering from different "Skin related Problems" are arranged in the form of matrix as shown below depending on the nature of response observed in the subjects against the given treatment.

$$
\text { Matrix } \left.=10 \begin{array}{ccccc}
0 & 1 & 2 & 3 & 4 \\
0 & 13 & 49 & 56 & 0 \\
13 & 0 & 8 & 0 & 0 \\
0 & 0 & 57 & 0 & 0 \\
0 & 0 & 0 & 56 & 0 \\
0 & 0 & 0 & 0 & 0
\end{array}\right)
$$

and associated one-step t.p.m is as given below

$$
\left.\mathrm{P}_{3}=10 \begin{array}{ccccc}
0 & 1 & 2 & 3 & 4 \\
0 & 1 \\
3 & 0.11 & 0.41 & 0.48 & 0 \\
0.61 & 0 & 0.39 & 0 & 0 \\
0 & 0 & 1 & 0 & 0 \\
0 & 0 & 0 & 1 & 0 \\
0 & 0 & 0 & 0 & 1
\end{array}\right)
$$

\subsection{Digestive problems:-}

Out of the total number of cases in 185 cases the subjects are suffering from different "Digestive Problems" are arranged in the form of matrix as shown below depending on the nature of response observed in the subjects against the given treatment. 


$$
\text { Matrix } \left.=1 \begin{array}{ccccc}
0 & 1 & 2 & 3 & 4 \\
0 & 3 & 78 & 100 & 4 \\
3 & 0 & 2 & 0 & 0 \\
3 \\
0 & 0 & 80 & 0 & 0 \\
0 & 0 & 0 & 100 & 0 \\
0 & 0 & 0 & 0 & 4
\end{array}\right)
$$

and corresponding one-step t.p.m is as given below

$$
\mathrm{P}_{3}=\begin{aligned}
& 0 \\
& 1 \\
& 2 \\
& 3 \\
& 4
\end{aligned}\left(\begin{array}{ccccc}
0 & 1 & 2 & 3 & 4 \\
0.6 & 0 & 0.4 & 0 & 0 \\
0 & 0 & 1 & 0 & 0 \\
0 & 0 & 0 & 1 & 0 \\
0 & 0 & 0 & 0 & 1
\end{array}\right)
$$

\subsection{Central Nervous System Problems:-}

Out of the total number of cases in 180 cases the subjects are suffering from different "Central Nervous System Problems" are arranged in the form of matrix as shown below depending on the nature of response observed in the subjects against the given treatment.

$$
\text { Matrix }=\quad \begin{aligned}
& 1 \\
& 3 \\
& 3 \\
& 3
\end{aligned}\left(\begin{array}{ccccc}
0 & 1 & 2 & 3 & 4 \\
0 & 17 & 75 & 78 & 10 \\
17 & 0 & 3 & 0 & 0 \\
0 & 0 & 78 & 0 & 0 \\
0 & 0 & 0 & 78 & 0 \\
0 & 0 & 0 & 0 & 10
\end{array}\right)
$$

The obtained one-step t.p.m is as given below

$$
\mathrm{P}_{3}=\begin{aligned}
& 0 \\
& 1 \\
& 2 \\
& 3 \\
& 0
\end{aligned}\left(\begin{array}{ccccc}
0 & 1 & 2 & 3 & 4 \\
0 & 0.09 & 0.41 & 0.45 & 0.05 \\
0.85 & 0 & 0.15 & 0 & 0 \\
0 & 0 & 1 & 0 & 0 \\
0 & 0 & 0 & 1 & 0 \\
0 & 0 & 1
\end{array}\right)
$$

Computation of probabilities of Recovery and death using the transition probability matrices obtained in section

\begin{tabular}{|c|c|c|c|c|c|}
\hline $\begin{array}{l}\text { Type } \\
\text { Problem }\end{array}$ & Respiratory Problems & $\begin{array}{l}\text { Orthopedic } \\
\text { problems }\end{array}$ & $\begin{array}{ll}\begin{array}{l}\text { Skin } \\
\text { problems }\end{array} & \text { related } \\
\end{array}$ & Digestive problems & $\begin{array}{l}\text { Central Nervous } \\
\text { System Problems }\end{array}$ \\
\hline$\xi_{1}$ & -1.1066 & -1.1674 & -1.2615 & -1.0991 & -1.2837 \\
\hline$\xi_{2}$ & -0.8905 & -0.8326 & -0.7385 & -0.9009 & -0.7162 \\
\hline $\mathrm{t}$ & $\begin{array}{l}{[3.282-1] * 7} \\
=15.96\end{array}$ & $\begin{array}{l}{[3.132-1] * 7=} \\
14.9198\end{array}$ & $\begin{array}{l}{[4-1] * 7} \\
=21\end{array}$ & $\begin{array}{l}{[2.95-1] * 7} \\
=13.653\end{array}$ & $\begin{array}{l}{[2.96-1] * 7} \\
=13.76\end{array}$ \\
\hline $\mathrm{P}_{2}(\mathrm{t})$ & 0.3678 & 0.5207 & 0.49078 & 0.4323 & 0.4686 \\
\hline $\mathrm{P}_{3}(\mathrm{t})$ & 0.5976 & 0.4735 & 0.5094 & 0.5459 & 0.4709 \\
\hline $\mathrm{P}_{4}(\mathrm{t})$ & 0.0345 & 0.0058 & 0 & 0.0218 & 0.605 \\
\hline
\end{tabular}
5 , probabilities of recovery and death due to a specified type of disorder are computed with the help of Kolmogorov equations given in section 4. Computed values are presented in the following table.

Table 1 
Note that the Kolmogorov equations are functions of ' $t$ '. The average number of visits of dogs is taken as value of' $t$ '. It has been observed that there is a gap of 7days between two visits of dogs.

Hence,

$$
\mathrm{t}=[\text { average number of visits }-1] * 7
$$

\section{LIMITING BEHAVIOR:-}

For each transition matrix it's stationary distribution is obtained. Using stationary distributions once again probabilities that a subject can enter into states 2 or 3 or 4 , for each category of disorders for sufficiently large number of visits i.e., as $n \rightarrow \infty$.

6.1 Stationary distributions of 5categories of disorders are as given below.

$$
\begin{aligned}
& \left.\left.\pi_{1}=\begin{array}{ccccc}
0 & 1 & 2 & 3 & 4 \\
1 & 0 \\
3 & 4 \\
3 & 0 & 0.36 & 0.61 & 0.03 \\
0 & 0 & 0.68 & 0.31 & 0.01 \\
0 & 0 & 1 & 0 & 0 \\
0 & 0 & 0 & 1 & 0 \\
0 & 0 & 1
\end{array}\right) \quad \pi_{2}=\begin{array}{c}
0 \\
0 \\
0
\end{array}\right)
\end{aligned}
$$

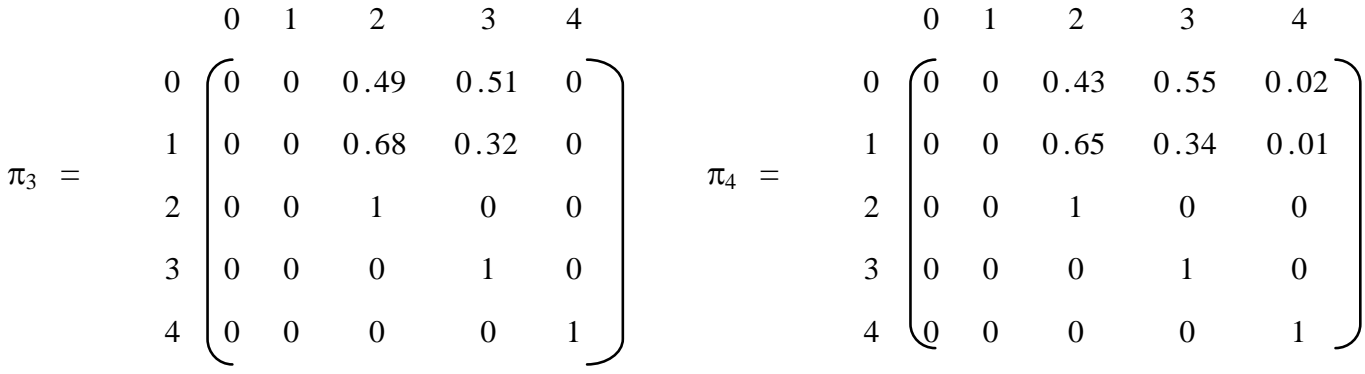

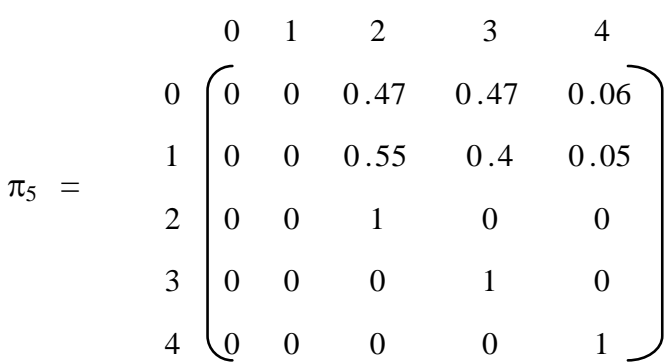

6.2 Probabilities of Recovery and Death using Stationary distributions:-

Computed values of probabilities using stationary distributions are presented in the following of table.

Table 2

\begin{tabular}{|l|l|l|l|l|l|}
\hline $\begin{array}{l}\text { Type } \\
\text { Problem }\end{array}$ & Respiratory Problems & $\begin{array}{l}\text { Orthopedic } \\
\text { problems }\end{array}$ & $\begin{array}{l}\text { Skin related } \\
\text { problems }\end{array}$ & Digestive problems & $\begin{array}{l}\text { Central Nervous } \\
\text { System Problems }\end{array}$ \\
\hline $\mathrm{t}$ & 15.96 & 14.9 & 21 & 13.7 & 13.76 \\
\hline$\xi_{1}$ & -1 & -1 & -1 & -1 & -1 \\
\hline$\xi_{2}$ & -0.6839 & -0.705 & -0.6846 & -0.6594 & -0.5474 \\
\hline $\mathrm{P}_{2}(\mathrm{t})$ & 0.3677 & 0.5206 & 0.49059 & 0.43229 & 0.4685 \\
\hline $\mathrm{P}_{3}(\mathrm{t})$ & 0.5976 & 0.4734 & 0.50929 & 0.54579 & 0.4709 \\
\hline $\mathrm{P}_{4}(\mathrm{t})$ & 0.03449 & 0.0058 & 0 & 0.0217 & 0.0604 \\
\hline
\end{tabular}




\section{CONCLUSIONS}

From the statistical analysis, the following conclusions are made.

1. The two probabilities $\mathrm{P}_{2}(\mathrm{t})$ ( probability of $100 \%$ cure ) and $\mathrm{P}_{3}(\mathrm{t})$ ( probability of cured to the extent curable ) put together can be termed as "Efficiency of Homeopathy medicine in curing different types of problems in Pet dogs". In all the types of disorders $\mathrm{P}_{2}(\mathrm{t})+\mathrm{P}_{3}(\mathrm{t})$ is more than .90 i.e., Efficiency of Homeopathy medicine is curing different diseases of Pet dogs is more than $90 \%$

2. Since the Probabilities $\mathrm{P}_{2}(\mathrm{t}), \mathrm{P}_{3}(\mathrm{t})$ and $\mathrm{P}_{4}(\mathrm{t})$ are same for stationary distributions and one-step transition probabilities, the sample size taken is sufficiently large. Hence, from this analysis general inference can be made on Homeopathy treatment for Pet dogs.

\section{REFERENCES}

[1].

Fix E and Neyman, J. (1951) -

[2]. A Simple Stochastic Model of Recovery, Relapse, Death and Loss of Patients, Human Biol. 23, 205-541.

Stochastic Processes by U. Narayana Bhat. Wiley Series in Probability and Mathematical Statistics.

Elements of Applied 